\title{
Selection of Natural Fruit Ingredients for the Production of Wine Cocktails with High Organoleptic Properties
}

\author{
N.R. Simonyan, A.K. Solomonyan \\ Armenian National Agrarian University \\ nunesim@mail.ru, solomonyan.2017@mail.ru
}

\section{A RT ICLE INFO}

Keywords: natural fruits, fruit ingredients, wine cocktail, chemical indices, organoleptic properties

\begin{abstract}
A B S T RACT
The aim of the research is to identify and select natural fruit ingredients for the production of wine cocktails with high organoleptic properties via investigating the chemical and organoleptic indices of the produced cocktails. Dried apricots and kumquat fruits have been selected as fruit ingredients. They have been mixed with the dry white wine materials with the doses of $10 \mathrm{~g} / \mathrm{dm}^{3}$ and $20 \mathrm{~g} / \mathrm{dm}^{3}$ respectively.
\end{abstract}

\section{Introduction}

The consumption and target areas of the contemporary alcoholic products are quite different. There are many lowalcohol beverages in the world market the list of which has been headed by the beer products for many years. Currently, energy drinks and cocktails are alternatives to beer, and due to the low alcohol and sugar content they are in high demand among the consumers (Samuel and Znak, 1994).

Due to the combination of wine with other drinks (alcoholic and non-alcoholic) it becomes possible to develop new technologies for palatable cocktail production. Many of these recipes have become famous worldwide, while some of them are quite new and haven't gained wide consumption frames yet (Borisenko, 2002).

The cocktails available in the domestic and foreign markets contain only liquid ingredients. Besides, the beverages with no synthetic food additives and multi distilled ethyl alcohol are of special significance. The production of wine cocktails with solely natural raw material and with higher organoleptic properties (appearance and taste) is an issue to be addressed by both the consumers and the branch industry.

\section{Materials and methods}

For the production of wine cocktails dry table wine material extracted from the grape, fresh citrus (kumquat fruits), dried apricots, grapes and apples prepared in natural conditions have been used (Burich, 1978). All ingredients complied with the requirements set for these products in the Republic of Armenia.

The dried fruits were sorted, washed and treated in microwave oven with high frequency radiation (Artikov, 1992). Each of the selected ingredients was placed in an individual container and then they were supplemented 
with wine material. Different doses of wine material $\left(5 \mathrm{~g} / \mathrm{dm}^{3}, 10 \mathrm{~g} / \mathrm{dm}^{3}, 20 \mathrm{~g} / \mathrm{dm}^{3}, 30 \mathrm{~g} / \mathrm{dm}^{3}\right)$ were applied for each dried fruit variety. The optical density of the obtained solution ceased to change 5-6 days after its production in case of two wavelengths $(420 \mathrm{~nm}$ and $520 \mathrm{~nm}$ ) of spectrophotometer. Just at this moment of physical equilibrium the mass concentration of dry matters and titratable acids was determined (Artikov, 1992).

Dried apricot, grape and apple fruits, kumquat fruits, dry white table wine material (control variant), the mixtures of fruit ingredients and different doses of wine materials, as well as wine cocktails have served as a study object.

The humidity and sulfur anhydrite of dried fruits and kumquat fruits, their sugar content, chemical indices of dry matters in white table wine, the mass concentrations of titratable acids and dry matters of fruit ingredient and wine material mixtures, as well as chemical indices and bottling stability of wine cocktails have been investigated. All investigated samples have been subjected to degustation.

The generally accepted standard methods stated in the normative documents and in winemaking branch currently practiced in Armenia have been applied for the research (Simonyan and Manukyan, 2011).

The organoleptic evaluation of the wine cocktails produced in the result of the experiments and available in the domestic market has been conducted by the professional degustation committee consisting of 10 members with 10-point rating scale (Simonyan and Manukyan, 2011, AST 271-2007: The alcohol production and raw material for its manufacture, methods for determination of titrating acids).

\section{Results and discussions}

The tasted wine cocktail samples available in the market were endowed with disadvantages peculiar to grape or fruit wine materials, i.e., lack of taste completeness and the presence of oxidized hues in the taste and flavor. In the foreign sample unpleasant bitter taste was felt due to the use of synthetic colorants and flavorings. Hence, by rejecting the use of synthetic components, the wine cocktail production could obtain an attractive direction.

The fruit ingredients of the wine cocktail meet the requirements set for their physicochemical properties (Table 1).

Table 1. The physicochemical indicators of the fruit ingredients in wine cocktails*

\begin{tabular}{|l|c|c|c|c|}
\hline \multicolumn{1}{|c|}{ Indicators } & Raisin & $\begin{array}{c}\text { Fried } \\
\text { apricots }\end{array}$ & $\begin{array}{c}\text { Dried } \\
\text { apples }\end{array}$ & Kumquat \\
\hline Humidity mass, \% & 17 & 19 & 19 & 80 \\
\hline Sulfur anhydrite, \% & 0.01 & 0.01 & 0.01 & 0.01 \\
\hline Sugar substances, \% & 30 & 35 & 12 & 9 \\
\hline *Composed by the authors. & & & \\
\hline
\end{tabular}

The dry wine material of the white grape applied for the cocktail production was endowed with the organoleptic properties peculiar to white wine materials and had the following chemical composition: ethyl alcohol - $9.5 \%$, mass concentration of the titratable acids - $7.2 \mathrm{~g} / \mathrm{dm}^{3}$, sugar mass concentration $-2.7 \mathrm{~g} / \mathrm{dm}^{3}$.

The changes of dry matters and titratable acids mass concentration in the mixture of wine materials and fruit ingredients depending on the doses of fruit ingredients are introduced in Table 2.

Table 2. The changes of dry matter and titratable acid mass concentration in the mixture of wine materials and fruit ingredients depending on the doses of fruit ingredients*

\begin{tabular}{|c|c|c|c|c|c|c|c|c|}
\hline \multirow{3}{*}{ Ingredients } & \multicolumn{8}{|c|}{ Doses of fruit ingredients, $\mathrm{g} / \mathrm{dm}^{3}$} \\
\hline & \multicolumn{4}{|c|}{ Mass concentration of dry matters, $\%$} & \multicolumn{4}{|c|}{ Mass concentration of titratable acids, $\mathrm{g} / \mathrm{dm}^{3}$} \\
\hline & 5 & 10 & 20 & 30 & 5 & 10 & 20 & 30 \\
\hline Dried apricots & 8.6 & 10.2 & 14.1 & 15.3 & 5.8 & 6.3 & 6.2 & 6.5 \\
\hline Raisin & 10.4 & 12.2 & 12.5 & 17.6 & 5.2 & 6.1 & 6.2 & 6.5 \\
\hline Dried apples & 9.6 & 10.7 & 12.7 & 16.7 & 6.0 & 6.3 & 6.8 & 6.7 \\
\hline Citrus (kumquat fruit) & 7.0 & 7.5 & 10.4 & 12.3 & 5.8 & 5.8 & 5.9 & 6.2 \\
\hline Control sample & \multicolumn{4}{|c|}{6.8} & \multicolumn{4}{|c|}{5.8} \\
\hline
\end{tabular}


Table 3. Qualitative indices of wine cocktails*

\begin{tabular}{|c|c|c|c|c|}
\hline \multirow[b]{2}{*}{ Indicator } & \multicolumn{4}{|c|}{ Wine cocktails } \\
\hline & $\begin{array}{l}\text { With dried } \\
\text { apricots }\end{array}$ & With raisin & $\begin{array}{l}\text { With dried } \\
\text { apples }\end{array}$ & With kumquat \\
\hline Ethyl alcohol volume, \% & 8 & 8 & 8 & 7 \\
\hline Mass concentration of sugars, $\mathrm{g} / \mathrm{dm}^{3}$ & 50 & 50 & 45 & 45 \\
\hline Mass concentration of titratable acids, $g / \mathrm{dm}^{3}$ & 5.0 & 4.3 & 4.6 & 5.5 \\
\hline Mass concentration of the total sulfur dioxide, $\mathrm{mg} / \mathrm{dm}^{3}$ & 138.2 & 145.7 & 143.2 & 125.6 \\
\hline Degustation evaluation, point & 8.4 & 8.3 & 8.2 & 8.4 \\
\hline Bottling stability & $\begin{array}{c}\text { No more than } 6 \\
\text { months }\end{array}$ & $\begin{array}{c}\text { No more than } 6 \\
\text { months }\end{array}$ & $\begin{array}{l}\text { No more than } \\
6 \text { months }\end{array}$ & $\begin{array}{c}\text { No more than } 8 \\
\text { months }\end{array}$ \\
\hline
\end{tabular}

Upon the interfusion of kumquat fruits and wine material it became clear that when increasing the fruit dose up to $20 \mathrm{~g} / \mathrm{dm}^{3}$, the organoleptic indicators also improve, but in case of $30 \mathrm{~g} / \mathrm{dm}^{3}$ the wine material acquired bright citrus tints and yellow coloring. Extraction of dry matters was also observed; their quantity increased in about 1.7 times, besides, the mass concentration of the titratable acids almost remained unchanged.

In the result of raisin and wine material interfusion raisining hues in the flavor and taste were recorded when preparing solution with $5 \mathrm{~g} / \mathrm{dm}^{3}$ and $10 \mathrm{~g} / \mathrm{dm}^{3}$ doses of raisin, while in case of applying $20 \mathrm{~g} / \mathrm{dm}^{3}$ and $30 \mathrm{~g} / \mathrm{dm}^{3}$ ingredient, unpleasant sweetness and bitter aftertaste was felt. Growth in the mass concentration of the dry matters was recorded and the acidity increased by $0.7 \mathrm{~g} / \mathrm{dm}^{3}$.

Similar organoleptic patterns have been recorded in case of applying dried apricots and apples.

The most intensive growth in the content of dry matters has been observed upon the interfusion of dried apples and wine material, when the increase of titratable acidity amounted to $0.7 \mathrm{~g} / \mathrm{dm}^{3}$.

The favorable dose for the kumquat fruits as a fruit ingredient is assumed as $20 \mathrm{~g} / \mathrm{dm}^{3}$, while for the dry apricots and apples it is $10 \mathrm{~g} / \mathrm{dm}^{3}$.

The qualitative indicators of the wine cocktail are introduced in Table 3. The highest organoleptic indices have been recorded in the cocktails produced via citrus fruit and dry apricots. They were distinguished by typical consistent fruit flavor. These ingredients can be used in the recommended technology of wine cocktail production.
The demand for such product types is drastically growing in the world market; anyhow they haven't found broad application in Armenia yet. Thus, the methods and technology recommended in the current article could greatly contribute to the branch development.

\section{Conclusion}

Based on the retrieved experimental data, it can be inferred that dry matter extraction upon the interfusion of citrus and wine material is recorded; its amount increases in 1.7 times as a result of which the mass concentration of the titratable acids almost stays unchanged. An increase in the mass concentration of dry matters is also observed upon the interfusion of wine material and raisin in case of which the titratable acidity grows up by $0.9 \mathrm{~g} / \mathrm{dm}^{3}$. The most intensive growth in the content of dry matters is recorded when using dried apples in case of which the titratable acidity increases by $1 \mathrm{~g} / \mathrm{dm}^{3}$.

The organoleptic analysis of semi-finished products has indicated that in case of increasing the doses of all ingredients, organoleptic indicators improve, as well as intensification of sweetness and bitter aftertaste is felt.

It has been also found out that in case of citrus and wine material interfusion, well distinguished bright citrus tints and yellowish color emerge.

The demand for such products is rapidly growing in the world market but they aren't widely used in Armenia yet. Hence the recommended technology could surely promote the branch development. 


\section{References}

1. Artikov, A.A. (1992). Electrophysical Methods of Food Exposure / A.A. Artikov // Tashkent: UzAS, -110 p.

2. AST 271-2007: The Alcohol Production and Raw Material for its Manufacture, Methods for Determination of Titrating Acids.

3. Borisenko, A.V. (2002). Low Alcohol Cocktails. Prospects for the Russian Market / A.V. Borisenko, Yu.I. Alekseeva, T.A. Kokina // Beer and Beverages - № 2 - p. 84.
4. Burich, O., Berki, F. (1978). Dried Fruits and Vegetables / O. Burich, F. Berki / Translated from Hungarian (Budapest, 1974), - M., - 280 p

5. Samuel, S.P., Znak, E. K. (1994). Alcoholic Beverages: Popular Encyclopedia / Editorial Board: S.P. Samuel, E.K. Znak/ M.: MET, - 352 p.

6. Simonyan, N.R., Manukyan, G.S. (2011). Wine Technology. Methodical Guidelines for Conducting Laboratory Works.- Yerevan - ASAU, - 32 p. 